\title{
MAJOR CO-MORBIDITIES IN STROKE PATIENTS: A HOSPITAL BASED STUDY IN BANGLADESH
}

\author{
BA MONDAL $^{1}$, RN CHOWDHURY ${ }^{2}, \mathrm{KM} \mathrm{RAHMAN}^{3}, \mathrm{SU}_{\mathrm{KHAN}}^{4}, \mathrm{ATMH} \mathrm{HASAN}^{5}, \mathrm{MA} \mathrm{HOQUE}^{6}$, B

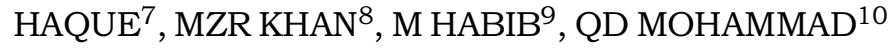

\begin{abstract}
:
Objective: To evaluate comprehensively all the major co morbid diseases seen in stroke patients.

Methods: In this observational study, 4579 patients were recruited from outdoor based stroke clinic in a tertiary care hospital. Twelve common co morbid conditions were evaluated in these patients through a preformed questionnaire and data were then analyzed.

Result: Hypertension was the most frequent co morbid condition found in stroke patients (57.6\%) followed by diabetes (23\%), ischemic heart disease (17.1\%), obesity (10.6\%) rheumatologic disorder (6.6\%) and dyslipidaemia (5.3\%). All the above other than rheumatologic disorder were significantly associated with stroke. There was no significant sex difference among co morbid conditions except obesity, which is more common in female ( $p$ value $=0.000$ ).

Conclusion: Stroke patients should be searched for co morbid diseases. As they may affect functional outcome during the period of rehabilitation, physicians should pay special attention in managing them properly.
\end{abstract}

Key Words: Ischemic stroke (ISC), Haemorrhagic stroke (HRG), Hypertension (HTN), Diabetes Mellitus (DM), Chronic kidney disease (CKD)

J Dhaka Med Coll. 2012; 21(1) : 16-22.

\section{Introduction:}

Stroke is defined as sudden onset of focal neurologic deficit of non traumatic cerebral vascular origin which persists for more than 24 hours. It is the second commonest cause of death $(9 \%)$ and a major cause of disability worldwide ${ }^{1}$. The age adjusted annual death rate from stroke in UK is about 200 per 100,000 (12\% of all death) ${ }^{1}$. Annually 16.3 million people suffer from stroke worldwide, among which 11.2 million events occur in developing countries like ours and about 5.8 million people die of stroke each year, the two third of which occurs in developing nations ${ }^{2}$. An estimated 64.5 million stroke patients survived an acute stroke event and living with varying degree of disability $^{2}$. The burden is projected to rise from 38 million DALY (Disability Adjusted Life Year) in 1990 to 61 million DALY in $2020^{3}$. The term "comorbidity" refers to one or more other disease among people with an index disease ${ }^{4}$. It is often difficult to determine whether a

1. Dr Md Badrul Alam Mondal, MBBS MD (Neurology), Associate Professor of Neurology, Dhaka Medical College Hospital

2. Dr Rajib Nayan Chowdhury, MBBS MCPS FCPS (Med) MD (Neurology), Assistant Professor of Neurology, Dhaka Medical College Hospital

3. Dr Kazi Mohibur Rahman, MBBS MD (Neurology) FINR (India), Assistant Professor of Neurology, Dhaka Medical College Hospital

4. Dr Sharif Uddin Khan, MBBS MD (Neurology) FINR (India), Assistant Professor of Neurologym, Dhaka Medical College Hospital

5. Dr A T M Hasibul Hasan, MBBS, Medical Officer, OPD Medicine, Dhaka Medical College Hospital

6. Dr Md Azharul Hoque, MBBS FCPS (Med) MD (Neurology), Associate Professor of Neurology, Dhaka Medical College Hospital

7. Dr Badrul Haque, MBBS PhD, OSD DG Health, attached to Dept of Neurology, Dhaka Medical College Hospital

8. Dr Muhammad Zillur Rahman Khan, MBBS MPH FCPS (Psychiatry), Assistant Professor, Dept of Child, Adolescent and Family Psychiatry, National Institute of Mental Health

9. Professor Mansur Habib, MBBS FCPS (Med) MD (Neurology) MRCP (UK) FRCP (Edin), Professor of Neurology, Dhaka Medical College Hospital,

10. Professor Quazi Deen Mohammad, MBBS FCPS (Med) MD (Neurology) Fellow of Neurology (USA), Professor \& Head, Dept of Neurology, Dhaka Medical College Hospital

Correspondence : Dr Rajib Nayan Chowdhury, Assistant Professor of Neurology, Dhaka Medical College Hospital. Email: rajibchow86@yahoo.com,01715176567 
clinical entity should be marked as comorbidity or complication of the disease itself. The working definition of complication is regarded as existence of a second disease when the occurrence of an index disease is required ${ }^{5}$. Comorbidity is a common phenomenon in elderly ${ }^{6}$. The fraction of senior citizens is expected to increase up to $19-26 \%$ within $2025^{7}$. The incidence of stroke also rises steeply with age $^{8}$. There is high incidence of coexisting medical disorders among patients recovering from stroke. In general these coexistent medical conditions have a negative impact on disease outcome and quality of life ${ }^{9}$. In our study we tried to identify the probable co morbid conditions in stroke patients who attended a specialized stroke clinic at Neurology outpatient department of Dhaka Medical College Hospital. The optimal management of these conditions may accelerate recovery from stroke during the phase of rehabilitation ${ }^{10}$.

\section{Materials and Methods:}

This is an observational study carried out in weekly Stroke outdoor clinic of Department of Neurology, DMCH from October 1996 to July 2011. During this period a total of 57821 patients with neurological complaints were seen in Neurology OPD of DMCH. Among them 4579 patients of stroke were enrolled for the study using a preformed questionnaire. Required information on age, sex, social status, presence of co morbid conditions eg, hypertension, diabetes, obesity, smoking, dyslipidaemia, heart disease, lung disease, renal problem, rheumatologic disorder, malignancy etc were noted. Patients were examined by research assistants. Diagnosis was made following WHO definition of stroke and the ICD-10 (chapter-VI) criteria and confirmed by CT scan of Head. MRI of brain was done in required cases. Patients were later evaluated and treated by consultant neurologists.

\section{Result:}

In our study 3527 patients (77\%) presented with ischemic stroke and 1052 patients (23\%) with hemorrhagic stroke (Figure-1). The frequency of stroke increased after the age of 40 years $(84.3 \%)$, the most common being in
51-60 years age group (31.1\%). But the occurrence of stroke somewhat decreased after sixty $(23.7 \%)$. Stroke events showed a male preponderance $(73.4 \%)$. The number of female stroke was 1216 (26.6\%) (Table-1). There was an increased frequency of haemorrhagic stroke in female patients in comparison to male counterpart. The male female ratio in ischemic subgroup was $3: 1$ and in haemorrhagic subgroup 2:1(Figure: 3 ). Hypertension was the most common co morbid condition in stroke patient $(56.7 \%)$. Most of them were known hypertensive (97.8\%). Only 56 patients $(2.2 \%)$ were diagnosed as hypertensive for the first time in stroke clinic. Majority of the patients took their antihypertensive medication regularly $(58.4 \%)$ except for $38.5 \%$ patients who had a history of taking irregular antihypertensive medication and $3.1 \%$ patients who did not take any medication at all (Table-II). Diabetes was the next common entity $(23 \%)$ in stroke patients after hypertension. They commonly took oral hypoglycemic agent (67.2\%). About $26.5 \%$ patients were on Insulin and $6.3 \%$ followed only dietary advice for controlling blood glucose level (Table-II). About $10.6 \%$ patients were morbidly obese. Ischemic heart disease was present in 781 stroke patients (17.1\%) and dyslipidaemia in $5.3 \%$. Rheumatologic conditions like osteoarthritis, low back pain and a few cases of inflammatory arthritis were present in $6.6 \%$ (301) patients. Respiratory disease in the form of bronchial asthma, chronic obstructive lung disease and pneumonia were found in $3.6 \%$ patients. Chronic kidney disease $(2.4 \%)$, electrolyte imbalance $(1.2 \%)$, thyroid disorder (1.5\%-mostly hypothyroidism), dementia (1.2\%) and malignancy $(0.2 \%)$ were found less commonly in our study (Table-II). Statistical analysis showed a strong association of hypertension, diabetes, ischemic heart disease, obesity and dyslipidaemia with stroke (Table-III). But there was no significant sex difference of these conditions except for obesity ( $p$ value- 0.000 ). About $16.9 \%$ of the female stroke patients were obese. Hypertension was also slightly more common among female $(60.2 \%)$. But the difference was not statistically significant (Table-III). 
Table I

Socio demographic profile of the patients $(N=4579)$

\begin{tabular}{lcc}
\hline Parameter & $\mathrm{n}$ & $\%$ \\
\hline Age & & \\
$11-20 \mathrm{yr}$ & 14 & 0.3 \\
$21-30 \mathrm{yr}$ & 141 & 3.1 \\
31-40yr & 561 & 12.3 \\
41-50yr & 1352 & 29.5 \\
$51-60 \mathrm{yr}$ & 1426 & 31.1 \\
$\quad$ >60 yrs & 1085 & 23.7 \\
Sex & & \\
$\quad$ Male & 3363 & 73.4 \\
$\quad$ Female & 1216 & 26.6 \\
Socioeconomic status & & \\
$\quad$ Lower & 1636 & 35.7 \\
$\quad$ Middle & 2924 & 63.9 \\
$\quad$ Higher & 19 & 0.4 \\
\hline
\end{tabular}

Table-I shows the demographic profile of stroke patients. Most of the patients are older than 40 years and male.

Table II

Major co morbid conditions $(N=4579)$

\begin{tabular}{lcc}
\hline Parameter & $\mathrm{n}$ & $\%$ \\
\hline Obesity & $\mathbf{4 8 6}$ & $\mathbf{1 0 . 6}$ \\
HTN & $\mathbf{2 6 3 8}$ & $\mathbf{5 7 . 6}$ \\
$\quad$ Previously diagnosed HTN & 2582 & 97.8 \\
$\quad$ Newly diagnosed HTN & 56 & 2.2 \\
Anti HTN Medication & & \\
$\quad$ Taking regularly & 1506 & 58.4 \\
$\quad$ Not taking & 81 & 3.1 \\
$\quad$ Irregularly taking & 995 & 38.5 \\
$\quad$ DM & 1055 & 23 \\
$\quad$ Previously diagnosed DM & 1014 & 96.1 \\
$\quad$ Newly diagnosed DM & 41 & 3.9 \\
Anti diabetic medication & & \\
$\quad$ Diet alone & 64 & 6.3 \\
$\quad$ OHA & 682 & 67.2 \\
Insulin & 268 & 26.5 \\
$\quad$ Smoking & 2041 & 44.6 \\
Ischemic Heart Disease & $\mathbf{7 8 1}$ & $\mathbf{1 7 . 1}$ \\
$\quad$ Dyslipidaemia & 244 & 5.3 \\
Rheumatologic Disease & 301 & 6.6 \\
Chronic Kidney Disease & $\mathbf{1 1 1}$ & $\mathbf{2 . 4}$ \\
$\quad$ Electrolyte Imbalance & 53 & 1.2 \\
Respiratory Disease & $\mathbf{1 6 5}$ & $\mathbf{3 . 6}$ \\
Thyroid Disorder & $\mathbf{6 7}$ & $\mathbf{1 . 5}$ \\
Dementia & $\mathbf{5 5}$ & $\mathbf{1 . 2}$ \\
Malignancy & $\mathbf{8}$ & $\mathbf{0 . 2}$ \\
\hline
\end{tabular}

Table-II Shows the major co morbid conditions in stroke patients. Hypertension, diabetes, ischemic heart disease, obesity and dyslipidaemia are five most common conditions.

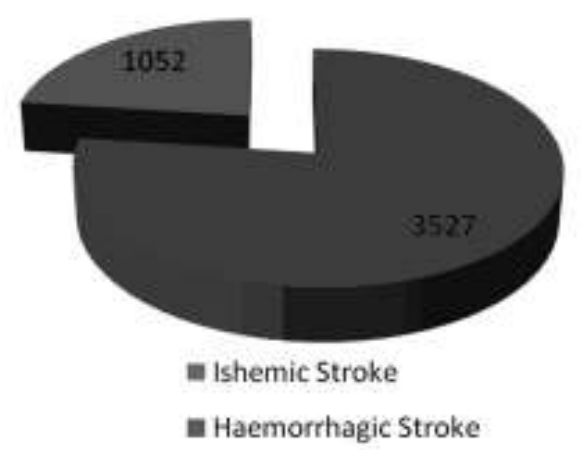

Fig.-1: Distribution of stroke subtype, showing that about $3 / 4^{\text {th }}$ of the patient had ischemic stroke

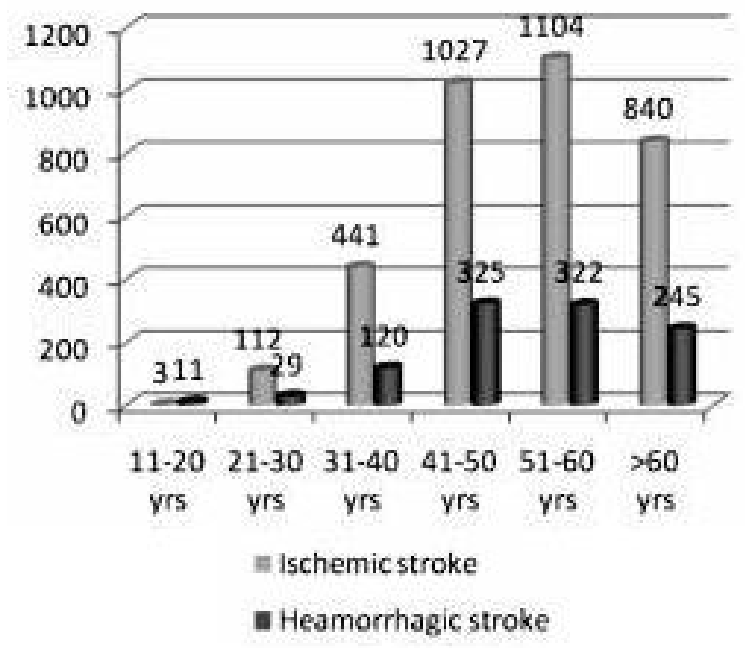

Fig.-2: The frequency stroke increased after 40 years and the ratio of ischemic and haemorrhagic stroke are nevertheless similar in all age group.

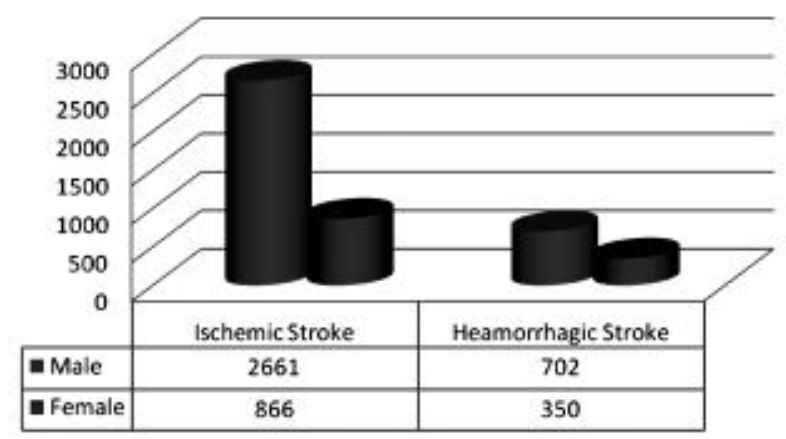

Fig.-3: The male to female ratio for haemorrhagic stroke is less than that for ischemic stroke which means, the female had relatively higher frequency of haemorrhagic stroke. 
Table III

Comorbidity and Stroke

\begin{tabular}{lcccccc}
\hline Parameter & \multicolumn{2}{c}{ Stroke Subtype* } & \multicolumn{3}{c}{ Sex } \\
& ISC & HRG & $p$ value & Male & Female & $p$ value \\
\hline Obesity & $7.5 \%$ & $3.1 \%$ & 0.001 & $8.3 \%$ & $16.9 \%$ & 0.000 \\
HTN & $43.3 \%$ & $14.3 \%$ & 0.0001 & $56.7 \%$ & $60.2 \%$ & 0.033 \\
DM & $20.1 \%$ & $2.9 \%$ & 0.0001 & $23.3 \%$ & $22.3 \%$ & 0.466 \\
IHD & $14.7 \%$ & $2.3 \%$ & 0.0001 & $17.8 \%$ & $15 \%$ & 0.023 \\
Dyslipidaemia & $3.7 \%$ & $1.7 \%$ & 0.002 & $5.1 \%$ & $5.8 \%$ & 0.355 \\
Rh. disease & $5 \%$ & $1.6 \%$ & 0.687 & $6.5 \%$ & $6.9 \%$ & 0.589 \\
CKD & $1.9 \%$ & $0.5 \%$ & 0.602 & $2.4 \%$ & $2.5 \%$ & 0.740 \\
Resp disease & $2.6 \%$ & $1 \%$ & 0.087 & $3.5 \%$ & $3.9 \%$ & 0.473 \\
Thyroid disorder & $1.2 \%$ & $0.3 \%$ & 0.321 & $1.4 \%$ & $1.6 \%$ & 0.780 \\
Dementia & $1 \%$ & $0.2 \%$ & 0.395 & $1.3 \%$ & $0.9 \%$ & 0.356 \\
EI & $0.8 \%$ & $0.3 \%$ & 0.354 & $1.3 \%$ & $0.8 \%$ & 0.273 \\
Malignancy & $0.2 \%$ & 0 & 0.481 & $0.2 \%$ & $0.2 \%$ & 1.00 \\
\hline
\end{tabular}

* ISC= Ischemic stroke; HRG= Haemorrhagic stoke, EI= Electrolyte imbalance" Chi-square test with 95\% confidence interval

\section{Discussion:}

In this outdoor clinic based study, the ratio of ischemic $(77 \%)$ versus haemorrhagic $(23 \%)$ stroke was 3.34: 1 . The finding contradicted the study of Hossain at el and Alam, conducted in hospitalized patients of Dhaka Medical College, who showed the ratio of $1.5: 1$ in ischemic versus haemorrhagic stroke. ${ }^{11,12}$. But our report was similar to average ratio of stroke subtypes in ASEAN (Association of South East Asian Nations) countries ${ }^{13}$. But the country specific frequency of haemorrhagic stroke in hospital based study varies from $38.6 \%$ in Indonesia to $26 \%$ in Singapore ${ }^{13}$. Banerjee at el in community based study in Kolkata reported a ratio of $2.21: 1$ of stroke subtypes ${ }^{14}$. The trend of increased frequency of haemorrhagic stroke found in hospital based study is probably due to increased rate of hospitalization of haemorrhagic stroke patients as a result of acuteness in clinical presentation. But the hospital outdoor based study reflects the gross scenario of prevailing disease in the community. There is also a tendency of higher proportion of haemorrhagic stroke in developing countries than the western population. Most of the studies conducted in East Asia, reported a significantly higher frequency of intracerebral haemorrhage (up to $35 \%$ ) ${ }^{15}$. The majority of stroke patients were above 40 years of age which was similar to findings of dissertations of Arif, Bashar and Chowdhury ${ }^{16-18}$. Feigin et al in his report of 15 developed countries, showed a progressive increase of age specific incidence rate of stroke with each decade of life, the largest number being in people older than 85 years. The highest age specific stroke events occurred in Japan, Russia and Ukraine ${ }^{19}$. But in our series the stroke frequency decreased after 60 years of age. The difference from the developed countries accounts for the fact that average life expectancy is 65 years in Bangladesh. In this study the male to female ratio of stroke was $2.75: 1$. The finding differs significantly from a community based study in China that reported the ratio from 1.3-1.5:1 ${ }^{20}$. Though we found a significantly higher proportion of hemorrhagic stroke among female $(p=0.000)$, it demands further research to find out the cause beneath this relationship. Johansen et al also showed similar report from Canada where in each age group subarachnoid haemorrhage was more common among the female and the difference was statistically 
significant ${ }^{21}$. Hypertension was the most common co morbid condition among stroke patients $(57.6 \%)$. The finding is 1.8 times higher than the report of Johansen (35\%) 21 and 1.4 times less than the reports from Turkey $(83 \%)^{22}$. Diabetes, ischemic heart disease, obesity, dyslipidaemia are the other major co morbid conditions found in stroke patients and all these factors had statistically significant association with stroke. The reports are also similar to that of Johansen ${ }^{21}$ but differ slightly in terms of order of frequency of these factors from the study of Karatepe et $\mathrm{al}^{22}$. Nuyen et al found a different set of co morbid conditions in stroke patients. He reported Epilepsy, TIA, Congenital abnormalities, Parkinsons disease and blood pressure problems as the most common five conditions associated with stroke patients $^{23}$. Age, sex, hypertension, DM, heart disease, hyperlipidaemia are also established risk factors of stroke ${ }^{24}$. Wong at el showed that ischemic heart disease and diabetes were independent risk factors for early death in ischemic stroke patients. Hypertension and young age were protective whereas diabetes was risk factor for early death in haemorrhagic stroke patients ${ }^{25}$. There are very few studies available regarding co morbid conditions in stroke and their effect on functional outcome. Goldstein at el showed the functional outcome at discharge from hospital and 1year mortality was associated with the number and severity of co morbid conditions ${ }^{26}$. In another study, coronary artery disease and diabetes both predicted an unfavorable outcome ${ }^{27}$. There are some contradictory results published about co morbid disease and functional gain. Some authors suggested no relationship between functional gain and co morbidities while others showed the negative effect of co morbid conditions on functional outcome ${ }^{28-31}$. Most of the tools developed for measuring comorbidity are adapted for acute stroke patients who are hospitalized. Our study was a hospital outdoor based observation and we did not measure the co morbidities through any index. So their effect on functional outcome was not analyzed. Other than obesity and hypertension all the co morbid conditions were equally distributed among both the sex. The female had a higher frequency of obesity which was statistically significant $(p=0.000)$. But higher frequency of hypertension in female was proved statistically insignificant. Our finding contradicts to the community based study of Holroyed-Leduc et al in Canada where men were more likely to have ischemic heart disease and diabetes mellitus whereas women had higher prevalence of atrial fibrillation and hypertension ${ }^{32}$. The ethnic, geographic composition and nature of study might have contributed to the differences in observation. We certainly had some limitations in this study that warrant consideration. First of all, this is a hospital outdoor based study which excludes all the acute cases of stroke. Data were taken from patients during the period of rehabilitation. Secondly, we just noted the presence or absence of comorbid conditions but did not measure the disease severity through any scale and the effect of the conditions on functional outcome. Despite these limitations we tried to identify the common comorbid conditions in stroke patients that demands appropriate management for a better functional outcome in the long run.

\section{Conclusion:}

Co morbidities are common among stroke patients. The role of hypertension and diabetes on pathogenesis of stroke is well established. Ischemic heart diseases pose a great problem in treating haemorrhagic stroke patients. Obesity and dyslipidaemia are often found in stroke patients as a part of metabolic syndrome. As most of the patients are old, they often have osteoarthritis and other form of bone disease. Though the incidence of CKD, Lung diseases, electrolyte imbalance are not high enough, needs special attention to treat. Our study result should create awareness among physicians and care givers. This may improve the diagnosis and management of these conditions. Evidences are accumulating that there is negative impact of these conditions and functional recovery of stroke patients. Further studies should be carried out to determine the effect of these co morbid diseases on functional outcome of stroke patients in Bangladesh. 


\section{References:}

1. Kumar P, Clark M, Editors. Kumar \& Clark Clinical Medicine. $7^{\text {th }}$ edition. Spain: Elsevier limited; 2009: pp-1126.

2. Truelsen T, Bonita R. The worldwide burden of stroke: current status and future projections. In: Fisher M, editor. Handbook of Clinical Neurology, Elsevier B.V. 2009. vol 92(3 $3^{\text {rd }}$ series): pp-327-336.

3. Mackay J, Mensah GA. Global Burden of Stroke. In : The atlas of Heart Disease and Stroke (Partthree). World Health Organization: pp-50-51.

4. Feinstein AR. The pre-therapeutic classification of co-morbidity in chronic disease. J Chron Dis 1970; 23:455-69.

5. Schellevis FG. Comorbidity-definitions and methodological aspects. In: Chronic disease in general practice. Comorbidity and quality of care. (Thesis). Nijmegen: Catholic University Nijmegen: 1993.

6. Guralnik JM. Assessing the impact of comorbidity in the older population. Ann Epidemiol 1996; $6: 376-80$.

7. US Bureau of the Census. International Population Reports, An Aging World II. P25, 92-3. Washington, DC: US Government Printing Office, 1992.

8. Allen CMC, Lueck CJ, Dennis M. Neurologic disease. In: Colledge NR, Walker BR, Ralston SH, editors. Davidson's Principles and Practice of Medicine. $21^{\text {st }}$ edition. Elsevier Limited; 2010: pp1180

9. Gijsen R, Hoeymans N, Schellevis FG, Ruwaard D, Satariano WA, van den Bos GA. Causes and consequences of comorbidity: a review. J Clin Epidemiol 2001; 54:661-74.

10. Brandstater ME. Stroke rehabilitation. In: DeLisa JA, Gans BM, Walsh NE, Bockenek WL, Frontera WR, Gerber LH, et al. editors. Physical medicine $\&$ rehabilitation principles and practice. $4^{\text {th }}$ edition. Philadelphia: Lippincott Williams \& Wikins; 2005, p. 1655-1676.

11. Hossain AM, Ahmed NU, Rahman M, Islam MR, Sadhya G, Fatema K. Analysis of Sociodemographic and Clinical Factors Associated with Hospitalized Stroke Patient in Bangladesh. Faridpur Med Coll J 2011; 6(1): 19-23

12. Alam B. Stroke-Evaluation of Risk Factors. Bangladesh Journal of Neuroscience 1999; 15: 14-18.

13. Venketasubramanian N. Epidemiology of Stroke in ASEAN Countries-A review. Neurol J South East Asia 1998; 3: 9-14.
14. Banerjee TK, Mukherjee CS, Sarkhel A. Stroke in urban population of Calcutta- an epidemiological study. Neuroepidemiology 2001; 20: 201-7.

15. Sudlow CL, Warlow CP. Comparable studies of the incidence of stroke and its pathological subtypes: results from an international collaboration: International Stroke Incidence Colleboration. Stroke 1997; 28: 491-99.

16. Arif SM. A dissertation on study of risk factors of stroke in Bangladesh. 1993.

17. Bashar A. A dissertation on Study of risk factors of stroke. 1995; pp-78-80.

18. Chowdhury SMZ. A dissertation on study of risk factors in cerebrovascular disease. A study of 100 cases. $1991 ; \mathrm{p}-48$.

19. Feigin VL, Lawes CMM, Benette DA, Anderson CS. Stroke epidemiology: a review of population based studies of incidence, prevalence and case fatality in the late $20^{\text {th }}$ century. The Lancet Neurology, January 2003; 2: 43-52.

20. Liu M, Wu B, Wang WZ, Lee LM, Zhang SH, Kong LZ. Stroke in China: epidemiology, prevention and management strategies. Lancet Neurol 2007, 6: 456-64.

21. Johansen HL, Wielgosz AT, Nguyen K, Fry RN. Incidence, comorbidity, case fatality and readmission of hospitalized stroke patients in Canada. Can J Cardiol, 2006; 22 (1): 65-71.

22. Karatepe AG, Gunaydin R, Kaya T, Turkmen G. Comorbidity in patients after stroke: impact on functional outcome. J Rehabl Med 2008; 40: 83135.

23. Nuyen J, Schellevis FG, Satariano WA, Spreeuwenberg PM, Birkner MD, Vanden BGAM, Groenewegen PP. Comorbidity was associated with neurologic and psychiatric diseases: a general practice based controlled study. J Clin Epidemiol 2006; 59(12): 1274-84.

24. Smith WS, English JD, Johnston SC. Cerebrovascular Disease. In: Fauci AS, Braunwald E, Kasper DL, Hauser SL, Longo DL, Jasmeson $\mathrm{JL}$, Loscalzo J editors. Harrison's Principles of internal Medicine. $17^{\text {th }}$ Edition. The McGraw Hill 2008. p-2518.

25. Wong K.S. Risk factors for early death in acute Ischemic stroke and Intracerebral haemorrhage: a prospective hospital based study in Asia. Stroke 1999; 30: 2323-30.

26. Goldstein LB, Samsa GP, Matcher DB, Horner RD. Charlson Index comorbidity adjustment for ischemic stroke outcome studies. Stroke 2004; 35: 1941-45. 
27. Liu M, Tsuji T, Tsujiuchi K, Chino N. Comorbidities in stroke patients as assessed with a newly developed comorbidity scale. Am J Phys Med Rehabil 1999; 78: 416-24.

28. Giaquinto S. Comorbidity on post stroke rehabilitation. Eur J Neurol 2003; 10:235-38.

29. Gokkaya N, Aras M, Cardenas D, Kaya A. Stroke rehabilitation outcome: the Turkish experience. Int J Rehabil Res 2006; 29: 105-111.

30. Ferriero G, Franchignoni F, Benevolo E, Ottonello $\mathrm{M}$, Scocchi M, Michail X. The influence of comorbidities and complications on discharge functions in stroke rehabilitation inpatients. Eura Medicophys 2006; 42: 91-96.

31. Turhan N, Saraçgil N, Öztop P, Bayramoðlu M. Serum albumin and comorbidity relative to rehabilitation outcome in geriatric stroke, and possible links with stroke etiology. Int $\mathrm{J}$ Rehabil Res 2006; 29: 81-85.

32. Holroyed-Leduc JM, Kapral MK, Austin PC, Tu JV. Sex differences and similarities in the management and outcome of stroke patients. Stroke 2000; 31: 1833-37. 